University of Nebraska - Lincoln

DigitalCommons@University of Nebraska - Lincoln

U.S. National Park Service Publications and

Papers

National Park Service

$1-7-2020$

\title{
Plains Zebra (Equus quagga) Behaviour in a Restored Population Reveals Seasonal Resource Limitations
}

Charli de Vos

Stellenbosch University, charli.devos@andbeyond.com

Alison J. Leslie

Stellenbosch University, aleslie@sun.ac.za

Jason I. Ransom

United States National Park Service, jason_i_ransom@nps.gov

Follow this and additional works at: https://digitalcommons.unl.edu/natlpark

Part of the Environmental Education Commons, Environmental Policy Commons, Environmental Studies Commons, Fire Science and Firefighting Commons, Leisure Studies Commons, Natural Resource Economics Commons, Natural Resources Management and Policy Commons, Nature and Society Relations Commons, Other Environmental Sciences Commons, Physical and Environmental Geography Commons, Public Administration Commons, and the Recreation, Parks and Tourism Administration Commons

Vos, Charli de; Leslie, Alison J.; and Ransom, Jason I., "Plains Zebra (Equus quagga) Behaviour in a Restored Population Reveals Seasonal Resource Limitations" (2020). U.S. National Park Service Publications and Papers. 200.

https://digitalcommons.unl.edu/natlpark/200

This Article is brought to you for free and open access by the National Park Service at DigitalCommons@University of Nebraska - Lincoln. It has been accepted for inclusion in U.S. National Park Service Publications and Papers by an authorized administrator of DigitalCommons@University of Nebraska - Lincoln. 


\title{
Plains zebra (Equus quagga) behaviour in a restored population reveals seasonal resource limitations
}

\author{
Charli de Vos $^{\mathrm{a}}$, Alison J. Leslie ${ }^{\mathrm{b}}$, Jason I. Ransom ${ }^{\mathrm{c} \text { * }}$ \\ a Department of Conservation Ecology and Entomology, Stellenbosch University, Private Bag X1, Matieland 7602, South Africa \\ ${ }^{\mathrm{b}}$ Department of Conservation Ecology and Entomology, Stellenbosch University, Private Bag X1, Matieland 7602, South Africa \\ ${ }^{\mathrm{c}}$ National Park Service, 810 State Route 20, Sedro-Woolley, Washington 98284, USA
}

\section{A R T I C L E I N F O}

\section{Keywords:}

African wildlife

Animal behaviour

Conservation

Equine

Protected area management

\begin{abstract}
A B S T R A C T
A once abundant species, plains zebra (Equus quagga), is declining across much of sub-Saharan Africa. Reintroduction efforts at Majete Wildlife Reserve, Malawi, have resulted in rapid population increases, but little is known about how such populations resemble natural populations socially or behaviourally, and what those attributes may reveal about restoration success. Incorporating behavioural knowledge into conservation efforts is an important tool for managing the effects of habitat fragmentation and resource competition. The aim of this study was to quantify the daylight time budget of both family and bachelor bands of reintroduced plains zebra to determine if such behaviours resembled those found in natural populations, and to provide insights into seasonal behavioural patterns that could inform management strategies. We found that feeding occupied the largest percentage (mean $=41.8 \% \pm 2.36)$ of family band daylight time budgets, followed by resting $(18.5 \% \pm 2.21)$, locomotion $(10.9 \% \pm 1.05)$, vigilance $(7.5 \% \pm 0.92)$, maintenance $(2.7 \% \pm 0.92)$ and social behaviour $(1.4$ $\% \pm 0.33)$. Bachelor bands spent the majority of their daylight time being vigilant $(27.0 \% \pm 2.72)$, followed by locomotion $(21.0 \% \pm 2.05)$, feeding $(18.4 \% \pm 2.32)$, resting $(15.4 \% \pm 2.85)$, maintenance $(6.4 \% \pm 1.86)$ and social behaviour $(2.4 \% \pm 0.68)$. The time budgets of zebra in this restored population are generally congruent with those reported in natural populations of plains zebra. Seasonal variation in time spent feeding and resting, locomotion, and change in body condition, however, suggest that dry season resources may negatively impact zebra in the miombo savannah woodlands. These results provide important insights into resource implications for zebra in an ecological system with many large ungulate species that compete for forage, and may assist managers with resource management strategies.
\end{abstract}

\section{Introduction}

Plains zebra (Equus quagga) have historically represented one of the most abundant members of their ungulate communities in Africa, playing a vital role in maintaining the overall dynamics and well-being of the habitats they occupy (Hack et al., 2002). This species has experienced a $25 \%$ population decline across its range since 1992, and some populations have now been extirpated (King and Moehlman, 2016). As part of a large wildlife restoration initiative, African Parks Ltd. reintroduced 174 plains zebra into Majete Wildlife Reserve, Malawi, from 2004-2009. Survival and reproduction has been so successful that in 2017, Majete became a source population for other plains zebra restoration initiatives. At an ecological scale, however, it remains unknown how this restored population of zebra has socially organized themselves and if their behaviour reflects that of natural populations.
Gaining insights into how groups function and individuals behave can lead to better understanding of resource competition, foraging strategies, and habitat connectivity (King et al., 2016; Rubenstein, 2010).

Behavioural ecology is based on the fundamental idea that an animal's behaviour is a product of the features of their environment (Krebs and Davies, 1997). Therefore, changes in the environment should lead to changes in behaviour; otherwise it will result in reduced fitness (Rubenstein, 2010). Changes in behaviour can also lead to changes in the environment; for example, resource availability can be influenced and shaped by individual actions (Sibly and Smith, 1985). It has been posited that the natural social organization of plains zebra has evolved to overcome social and ecological problems, such as resource availability, bachelor harassment and predator pressures (Rubenstein and Hack, 2004).

Natural populations of plains zebra typically organize themselves

\footnotetext{
* Corresponding author.

E-mail addresses: charli.devos@andbeyond.com (C. de Vos), aleslie@sun.ac.za (A.J. Leslie), jason_i_ransom@nps.gov (J.I. Ransom).
} 
into a two-tiered structure: core social groups consisting of one male and many females (or many males without females) that form bands, and bands that merge together to form temporary herds (Hack et al., 2002; Klingel, 1969). Even though the social organization and population ecology of zebra has been thoroughly investigated (Ransom and Kaczensky, 2016), few studies on zebra have rigorously quantified behaviour or used behaviour as a measure of restoration success. In contrast, behaviour of other species (for example the African elephant [Loxodonta africana] and chimpanzee [Pan troglodytes]) has been meticulously investigated by numerous long-term studies, revealing characteristics overlooked by population-level studies and consequently improving conservation strategies (Simpson et al., 2012).

One of the methods used to study the behaviour of animals is quantifying time budgets, or how an animal spends its time, as defined by discrete behaviours (Ransom and Cade, 2009; King et al., 2016). Our study aimed to examine the behaviour of plains zebra in Majete Wildlife Reserve by quantifying time budgets to better understand if individuals in this restored population allocate their time and energy similar to individuals in natural populations, and how such behaviours may be influenced by environment. We hypothesized that the daylight time budget behaviours of zebra would be influenced by their sex, age, foal presence, body condition, group size, the time of day, and season. Since the reserve was fenced and migration not possible, we were able to continually observe a closed population over a 12-month period. The objective of this study was to assist management and conservation agencies in ensuring the future persistence of zebra in Majete 14 years after their initial reintroduction by incorporating better knowledge of behavioural ecology.

\section{Methods}

\subsection{Study area}

Majete Wildlife Reserve is located in southern Malawi's Lower Shire Valley region and covers $700 \mathrm{~km}^{2}$. The reserve has a semiarid climate and receives rainfall of $680-1000 \mathrm{~mm}$ a year, of which the majority occurs between December and April. Temperatures average $23.3^{\circ} \mathrm{C}$ in the winter (June to August) and $28.4{ }^{\circ} \mathrm{C}$ in the summer (December to February). Majete has a strong altitudinal gradient that increases from east to west and the two main perennial rivers, the Shire River and Mkulumadzi River, mark the northern and eastern borders. There are also ten artificial water points located within the reserve, and observation blinds overlook two of these. The vegetation is classified as miombo savanna woodland and can be divided into four distinct classes: savanna, high altitude miombo woodland, medium altitude woodland and high altitude woodland (de Vos, 2017).

In 1955, Majete was declared a game reserve; however, high levels of poaching and a lack of law-enforcement resulted in eradication of the majority of the large mammals from the reserve by the mid-1990s. In 2003, African Parks Ltd. and the Malawian Department of National Parks and Wildlife established a public-private partnership that aimed to rehabilitate the reserve. Majete is now a completely fenced reserve and 14 different mammal species have been reintroduced (over 2550 animals), making it one of Africa's largest wildlife reintroductions to date.

\subsection{Study subjects}

An aerial survey of Majete in 2015 detected 571 zebra (de Vos, 2017). From ground observations, we identified 243 unique individuals (roughly $40 \%$ of the population) using unique stripe patterns, including 168 adults with a sex ratio of 0.8:1.0 (male:female), 32 yearlings and 43 foals. We detected zebra across the entire reserve during this study (Fig. 1). Family band size ranged $2-11$ individuals (mean $=6.3 \pm 0.21$ [SE]) and each band was comprised of a single adult male with 1-5 adult females (mean $=2.8 \pm 0.10$ ) and their offspring. The number of yearlings observed within a single band ranged $0-3$ (mean = $0.6 \pm 0.09$ ) and the number of foals ranged $0-4$ (mean $=1.5 \pm 0.11$ ). Bachelor males were either observed alone or within groups ranging $2-8$ individuals (mean $=3.0 \pm 0.21$ ). We randomly selected 11 focal family bands consisting of 65 unique individuals, and 7 focal bachelor bands consisting of 29 unique individuals, and attempted to repeatedly observe them across all seasons.

\subsection{Behavioural sampling}

Behavioural observations were conducted between 08:00 $\mathrm{h}$ and 20:00 h over a 12-month period (22 April 2016-14 April 2017). All data were collected by the same observer (C. de Vos), accompanied by one or more assistants. Observations were either conducted on foot, from a vehicle, or an observation blind. Observation locations could not be randomly selected a priori due to the nature of wildlife moving around the landscape and selecting for specific resources; however, we collected data from across the entire reserve and across all seasons (Fig. 1). All observations on foot or from a vehicle were conducted from distances that did not draw the attention of the zebra to the presence of the observer. When conducting observations from a blind, the observers remained quiet and still to avoid drawing the attention of the wildlife. During each observation session, temporal (time and date), geographic (GPS coordinates and elevation) and climatic data (temperature, precipitation and cloud cover) were documented at the start of the observation period. The approximate distance of each observation, as well as the band size, band ID and band composition was also recorded.

Photographs of the group as a whole, and each individual zebra (from both sides), were taken with a Canon D700 DSLR camera (Canon, Inc., Tokyo, Japan). This allowed for individual identification of each zebra by comparing unique stripe patterns on their right and left sides to photographic records of the reserve's zebra, and allowed for additional photographic records of newly identified individuals and bands. Because each zebra was identified in all of the behavioural sessions conducted, the activities of specific individuals could be documented. The sex of each zebra was determined by examining the genitals, and the age class of each zebra was recorded as either: foal ( $0-12$ months), yearling (12-24 months) or adult (more than 24 months) according to Klingel (1969). We used a visual adaptation of the 0-9 body condition scale (emaciated to obese) of Henneke et al. (1983) as a basis for quantifying and assigning a body condition score for each individual observed in every behavioural session (sensu Rudman and Keiper, 1991; Ransom et al., 2010; Grange et al., 2015). Foal presence or absence was documented for adult females. Behavioural observations were recorded by digital video using the same camera for as long as the band could be followed. All behavioural sessions that persisted $\geq 15$ min were included in the analysis.

Video footage was analyzed to quantify time budgets of each individual zebra present within a band via instantaneous scan sampling at one minute intervals (as described in Ransom et al., 2010). Specific behaviours were defined and categorized into a set of nine mutually exclusive time budget categories (Table 1 ). In the rare case that an animal was observed doing two things at once, the predominant behaviour was recorded.

\subsection{Statistical analysis}

Discrete behaviours recorded at the 1-min scan sampling interval provided the systematic framework for quantifying how time was allocated, but such data are not independent; therefore, we transformed the sum of minutes that each behaviour was observed into its rate, given the total time of observation. The dependent variable in all statistical models was thus a rate by independent observation session.

All individual zebra present in a given band were sampled, but neither bands nor individuals were sampled equally across the entire study due to the nature of finding bands and ability of individuals to 


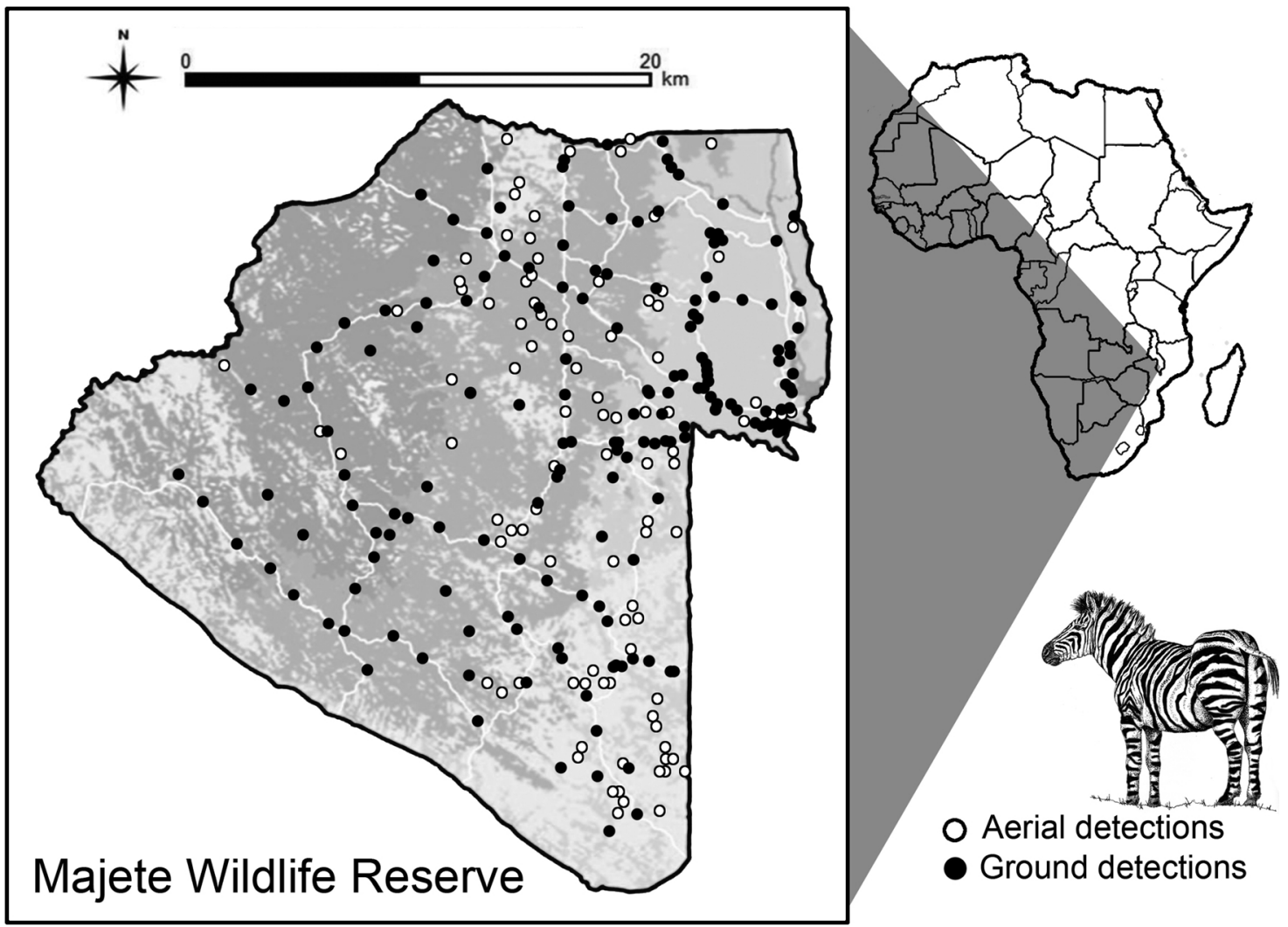

Fig. 1. Aerial $(\mathrm{O})$ and ground $(\bullet)$ detections of plains zebra (Equus caballus) in Majete Wildlife Reserve, Malawi, from aerial observation in 2015 and ground observations 22 April 2016-14 April 2017.

change bands between observations. The repeated and unequal measures were accommodated by incorporating individual identity as a random effect on the intercept of each linear model as described below. This allowed any effects arising from sampling frequency of some individuals to explicitly inform the estimated behaviour. This structure also allowed analyses to include a measure of variability among individuals that would otherwise not be captured (such as variation that might arise from age, experience, temperament, or genetics).

Because time of day is likely to influence some behaviours, we categorized observation time into three discrete periods (08:00-12:00 h, 12:01-16:00 $\mathrm{h}$ and 16:01-20:00 $\mathrm{h}$ ) and included this variable as an independent factor in the models. This broad categorical factor was intended to incorporate the potentially confounding factors of temperature, changing photoperiod, and predator activity that may temporally influence behaviour patterns. Some behaviours were also seldom detected and thus sample sizes were insufficient for modelling, but were functionally similar to other behaviours. We therefore grouped feeding and drinking behaviour into a single category for analysis (hereafter referred to as feeding behaviour). We also grouped vigilance behaviour and interspecific interactions into a single category for analysis (hereafter referred to as vigilance) because overt interactions with other species were very rare, but zebra being attentive when those species were nearby was common. Carnivores were only recently reintroduced into Majete and were so rare that only one of the 82 observed zebra interactions with other species included African lion (Panthera leo), and no other carnivores were detected. Preliminary analyses indicated that yearlings and adults did not behave differently in any behaviours measured and thus were grouped together for analysis (hereafter referred to as adults).

Time budget data are inherently compositional in nature; however, compositional analytical tools do not generally allow for detailed inference into factors influencing individual behaviours, especially when real values of 0 and 1 in a proportion exist (Ransom and Cade, 2009). As such, we modelled each time budget behaviour separately using the same linear mixed-effects model, but discuss the findings within the context of compositional dependence. We fitted hierarchical linear

Table 1

Behavioural categories used for classifying observations of plains zebra behaviour into discrete categories for analysis, derived from Ransom and Cade (2009).

\begin{tabular}{|c|c|}
\hline Behaviour Category & Included Behaviours \\
\hline Feeding & Grazing, browsing, coprophagy, soil ingestion, suckling, pawing at food resources \\
\hline Drinking & Actively drinking water, including temporary unfocused pause with mouth over water source \\
\hline Locomotion & Any form of movement, including walking, trotting, running, swimming (excluding locomotor play or interaction with another individual) \\
\hline Resting & Standing, sleeping, lying down, getting up, yawning, stretching \\
\hline Maintenance & Self-grooming, comfort (including sun-basking, object play, locomotor play, shelter-seeking, masturbation), excretion \\
\hline Vigilance & Standing attentive to stimuli (alertness, with rigid body posture, head upright, ears forward, eyes open and alert) \\
\hline Social & $\begin{array}{l}\text { All actions involving one or more other zebra, including herding, harem tending, allogrooming, reproduction, aggression, submission, conspecific urine } \\
\text { and feces investigation, chin-resting on conspecifics, pair-bonding among juveniles }\end{array}$ \\
\hline Interspecific Interaction & Interactions with other species, including directed focal attention and physical contact \\
\hline Unknown & $\begin{array}{l}\text { Focal animal moved out of sight during observation while other members of the band remained under observation, interaction with humans (i.e. } \\
\text { intervention with natural behaviour occurred) }\end{array}$ \\
\hline
\end{tabular}


mixed-effects models for the dependent variables of feeding, resting, locomotion, maintenance, vigilance, and social behaviour of family band zebra as a function of season ( $x_{1}$ : early wet, late wet, early dry, late dry), sex ( $x_{2}:$ male, female), age ( $x_{3}$ : adult, foal), foal presence $\left(x_{4}\right.$ : present, absent), body condition ( $x_{5}: 0-9$ score), group size ( $x_{6}$ : total number of zebra in the band), and time of day ( $x_{7}$ : as given above). In the notation of Gelman and Hill (2007), models took the form of $y_{\mathrm{k}[\mathrm{i}]}=$ $\alpha_{0 \mathrm{k}[\mathrm{i}]}+\beta_{0}+\beta_{x 1} x_{1[\mathrm{i}]}+\beta_{x 2} x_{2[\mathrm{i}]}+\beta_{x 3} x_{3[\mathrm{i}]}+\beta_{x 4} x_{4[\mathrm{i}]}+\beta_{x 5} x_{5[\mathrm{i}]}+$ $\beta_{x 6} x_{6[\mathrm{i}]}+\beta_{x 7} x_{7[\mathrm{i}]}+\varepsilon_{\mathrm{k}[\mathrm{i}]}$, where the random effect intercept of $\alpha_{1 \mathrm{k}[\mathrm{i}]} \sim$ $\mathrm{N}\left(\mu=0, \sigma_{\mathrm{k}}^{2}\right)$ represents $\mathrm{k}=1, \ldots, n$ individual zebra for $\mathrm{i}=1, \ldots n$ observations. This equation identifies the fixed effect intercept as $\beta_{0}, x=$ independent variable with parameter $\beta_{x}, \varepsilon=$ statistical error, and $y=$ the dependent variable (rate of behaviour observed).

A similar model was fit for bachelor band members, except that sex $\left(x_{2}\right)$ and foal presence $\left(x_{4}\right)$ were omitted as non-applicable. Because the same model was fitted for all behaviours to maintain compositional data perspective, and the complexities of interactive terms risked overparameterizing the model, we did not consider interactive terms a priori. We instead provide a limited supplemental a posteriori analysis to gain additional insights where the results suggested important interactions may be present.

We used the lmer package of $\mathrm{R}$ version 3.2.5 (The $\mathrm{R}$ Foundation for Statistical Computing, 2011) and Statistica version 13.2 (Dell Software, 2016) to calculate descriptive statistics and to obtain mixed-effects repeated measure model estimates. In the mixed-effects models, we used compound symmetry to model possible correlated observations.

\section{Results}

Behavioural data arose from a total of 4,048 zebra minutes (total band observation minutes times the number of focal animals in each band for each session) collected during 51 independent sessions. Each of the 11 focal family bands was sampled 1-10 times, and each of the 7 focal bachelor bands was sampled 1-12 times. Average length of a family band observation event was 101.3 \pm 11.87 min (range $=15-255$ min), and average length of a bachelor band observation event was $52.8 \pm 10.50 \mathrm{~min}$ (range $=15-240 \mathrm{~min}$ ). Each individual zebra was observed an average of $63.3 \pm 8.07 \mathrm{~min}$ (range $=15-203 \mathrm{~min}$ ). All individuals in family bands and bachelor bands were sampled only once per time period on a given day, with the exception of two occurrences where a family band was sampled twice (but not consecutively) within the same time period and 3 occurrences where a bachelor band was sampled twice (but not consecutively) within the same time period. Distribution of observation time by categorical variable included a minimum of 400 min across all categories in family bands, with observation time among bachelor bands being more variable (Table 2). During the observation sessions, temperatures ranged $18-41{ }^{\circ} \mathrm{C}$.

Table 2

The distribution of time budget observation sessions and total observed zebra minutes considered in mixed-effects linear models of time budget behaviours at Majete Wildlife Reserve, Malawi.

\begin{tabular}{|c|c|c|c|c|c|c|}
\hline & \multicolumn{2}{|c|}{ Family Bands } & \multicolumn{2}{|c|}{ Bachelor Bands } & \multicolumn{2}{|l|}{ Total } \\
\hline & Sessions & $\begin{array}{l}\text { Zebra } \\
\text { Minutes }\end{array}$ & Sessions & $\begin{array}{l}\text { Zebra } \\
\text { Minutes }\end{array}$ & Sessions & $\begin{array}{l}\text { Zebra } \\
\text { Minutes }\end{array}$ \\
\hline \multicolumn{7}{|l|}{ Season } \\
\hline Early Wet & 5 & 453 & 0 & 0 & 5 & 453 \\
\hline Late Wet & 11 & 1215 & 2 & 62 & 13 & 1277 \\
\hline Early Dry & 4 & 401 & 16 & 892 & 20 & 1293 \\
\hline Late Dry & 8 & 765 & 5 & 260 & 13 & 1025 \\
\hline \multicolumn{7}{|l|}{ Time Period } \\
\hline $08: 00-12: 00$ & 16 & 1544 & 10 & 446 & 26 & 1990 \\
\hline $12: 01-16: 00$ & 5 & 644 & 12 & 698 & 17 & 1342 \\
\hline $16: 00-20: 01$ & 7 & 646 & 1 & 70 & 8 & 716 \\
\hline Total & 28 & 2834 & 23 & 1214 & 51 & 4048 \\
\hline
\end{tabular}

Elevation was recorded between 122-229 m above sea level. During 1.9 $\%$ of the observational sessions precipitation occurred, $62.7 \%$ of the observational sessions had no cloud cover, $13.7 \%$ had partly cloudy conditions and $23.5 \%$ had cloudy conditions.

\subsection{Family band time budgets}

Feeding behaviour occupied the largest percentage (mean $=41.8$ $\% \pm 2.36$ ) of family band daylight time budgets (Fig. 2). The presence of a foal significantly influenced time spent feeding for zebra occurring in family bands $\left(F_{1,69}=11.25, P<0.001\right)$. Females with foals spent $20.0 \% \pm 5.58$ more time feeding than females without foals. The feeding behaviour of individuals in family bands was influenced by their age class $\left(F_{2,48}=6.23, P=0.02\right)$; with foals feeding 17.3 $\% \pm 6.74$ more during the day than adult zebra. The best predictor of the feeding behaviour for zebra living in family bands was the change in season $\left(F_{3,144}=10.27, P<0.001\right)$ (Fig. 3$)$. Family band zebra spent $43.5 \% \pm 15.78$ more time feeding during the early wet season than the early dry season. Group size, body condition, time period and sex were not significant predictors of the daylight feeding of family band zebra. The random effect of individual zebra identity on the model intercept did not meaningful influence any behaviours, and variance was minimal $\left(\sigma_{\mathrm{k}}^{2}<0.001\right)$.

Resting behaviour occupied the second largest percentage (18.5 $\% \pm 2.21$ ) of family band daylight time budgets (Fig. 2). The amount of time allocated to resting by family band members was $14.2 \% \pm 6.02$ lower during the late wet season compared to the early dry and late dry season $\left(F_{3,130}=6.06, P<0.001\right)$ (Fig. 3). Locomotion occupied an estimated $10.9 \% \pm 1.05$ of family band daylight time budgets and was affected by the season $\left(F_{3,147}=4.11, P=0.01\right)$. More daylight time (9.6-13.4 \% $\pm 2.81-4.31)$ was also allocated to locomotion during the late dry season compared to the other 3 seasons.

Vigilance behaviour occupied an estimated $7.5 \% \pm 0.92$ of family band daylight time budgets (Fig. 2). Age influenced the amount of daylight time spent being vigilant by family bands $\left(F_{1,68}=5.83, P=\right.$ 0.02 ), with adults vigilant $8.6 \% \pm 3.50$ more than foals. The vigilance behaviour of family bands was also influenced by the time of day $\left(F_{2,142}\right.$ $=3.21, P=0.04$ ), with more time allocated to vigilance during 08:00-12:00 h than 12:01-16:00 h or 16:01-20:00 h.

Maintenance occupied a relatively small amount of family band time budgets $(2.7 \% \pm 0.92)$ (Fig. 2). The amount of daylight time allocated to maintenance for family bands was influenced by the age of the individual $\left(F_{1,40}=4.55, P=0.04\right)$; with foals spending on average $4.1 \%$ more time on maintenance than adult zebra. Social behaviour occupied the smallest amount of family band daylight time budgets (1.4 $\% \pm 0.33$ ) (Fig. 2). For the remaining $17.3 \% \pm 1.90$, family bands were recorded as out of sight or interacting with humans (unknown natural behaviour).

\subsection{Bachelor band time budgets}

Bachelors spent the majority of their time being vigilant (27.0 $\% \pm 2.72$ ) (Fig. 2). The time bachelors allocated to vigilance was influenced by both the time period $\left(F_{2,64}=8.01, P<0.001\right)$ and season $\left(F_{2,64}=4.14, P=0.02\right)$. Bachelors allocated more time to vigilance behaviour from $16: 01-20: 00 \mathrm{~h}(61.8 \% \pm 10.43)$ than either 08:00-12:00 $\mathrm{h}$ or 12:01-16:00 h. They also spent more time being vigilant during the early dry season $(29.8 \% \pm 10.34)$ and late dry season $(29.4 \% \pm 14.56)$ compared to the late wet season. Like family bands, the random effect of individual zebra identity on the model intercept did not meaningful influence any behaviours $\left(\sigma_{\mathrm{k}}^{2}<0.001\right)$.

Locomotion behaviour also occupied a relatively large percentage of bachelor band daylight time budgets $(21.0 \% \pm 2.05)$, followed by feeding which occupied an estimated $18.4 \% \pm 2.32$ (Fig. 2). Resting behaviour occupied an estimated $15.4 \% \pm 2.85$ of bachelor time budgets and was influenced by body condition $\left(F_{1,64}=5.28, P=0.03\right)$. 


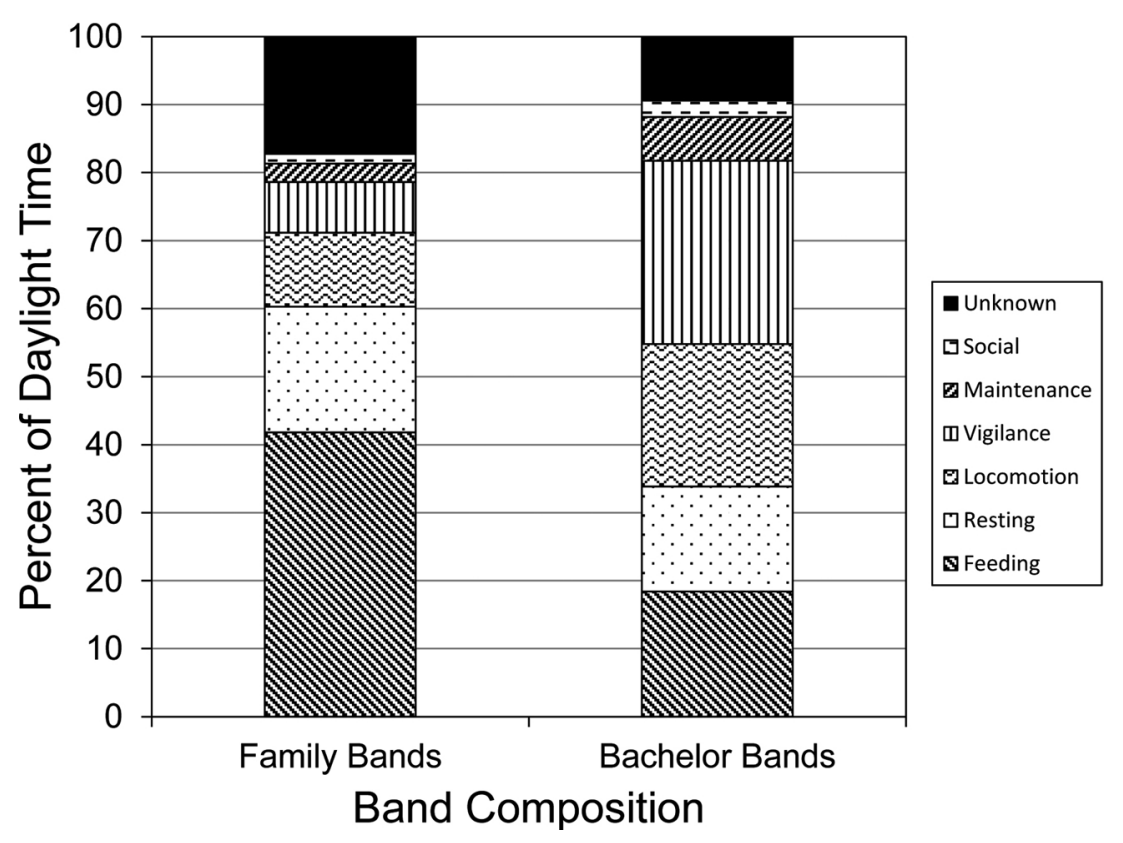

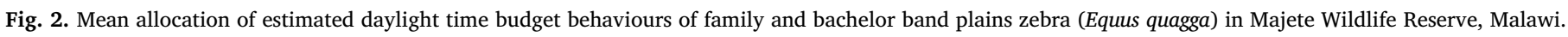

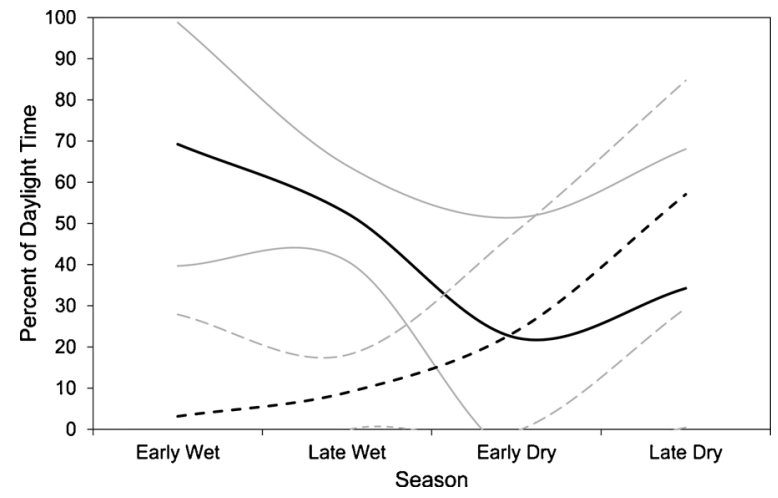

Fig. 3. Estimated percent of daylight time spent feeding (solid line, smoothed trend) and resting (dashed line, smoothed trend) as a function of season for individual plains zebra (Equus quagga) in family bands at Majete Wildlife Reserve, Malawi. Estimates are bounded in grey by a $95 \%$ confidence interval.

As body condition score increased from 3 to 6 , for example, the time allocated to resting decreased total of $25.8 \% \pm 11.04$.

A relatively small amount of bachelor zebra daylight time budget was allocated to maintenance behaviour $(6.4 \% \pm 1.86)$. Social behaviour occupied the smallest amount of time $(2.4 \% \pm 0.68)$ (Fig. 2). The remaining $9.7 \% \pm 1.74$ of bachelor band time budgets were recorded as out of sight or interacting with humans (unknown natural behaviour).

\subsection{Interactive factors}

Season was a significant factor influencing at least one behaviour in each compositional time budget for both family band members and bachelor band members. Because body condition may provide the most direct inference to fitness in our dataset, and season was a significant a priori influence on behaviour, we modelled body condition of adults a posteriori as a function of the interaction between season and group size, as well as band type (bachelor or family). We included band identification as a random effect to account for any influences that may have arisen from the relationships between individuals in groups that were sampled repeatedly. Group size was not predictive of individual behaviours a priori, but we suspected it may interact with season because group size has been shown to increase with increased competition for forage (Rubenstein, 1994). We found that mean body condition of all adults increased through the wet season and then declined rapidly as dry season progressed, irrespective of whether the individuals belonged to family bands or bachelor bands $\left(F_{3,157}=9.010\right.$, $P<0.001$ ). This trend was strongly influenced by the interaction between season and group size, with group size increasing as the dry season progressed in both family bands $\left(F_{3,93}=12.739, P<0.001\right)$ and bachelor bands $\left(F_{2,61}=3.309, P=0.04\right)$ (Fig. 4).

\section{Discussion}

\subsection{Family bands}

Family bands of plains zebra in Majete allocated the majority of their daylight time budgets to feeding behaviour $(41.8 \%$ of their daylight time budgets). In comparison, a previous study conducted by Neuhaus and Ruckstuhl (2002) on the daylight time budgets of plains zebra in Etosha National Park, Namibia, indicated that zebra spend the

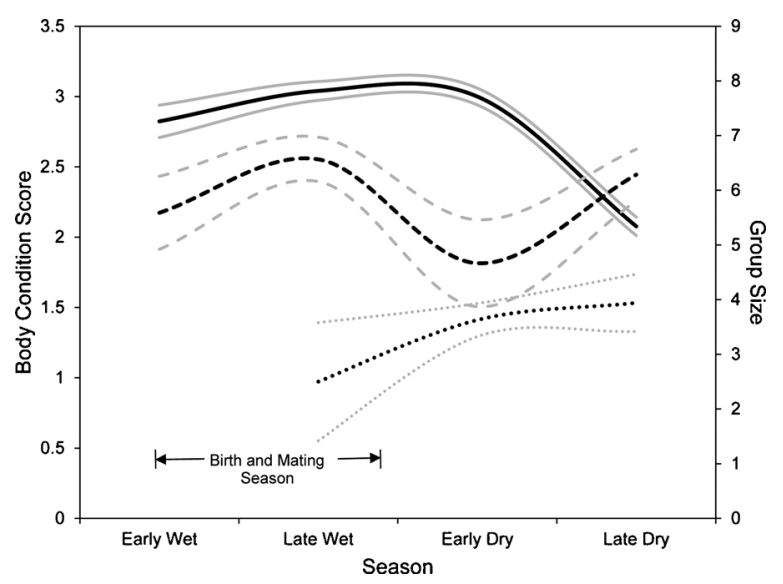

Fig. 4. Estimated mean body condition (solid line, smoothed trend) as a function of season for adult plains zebra (Equus quagga), and estimated group size of family bands (dashed line, smoothed trend) and bachelor bands (dotted line, smoothed trend) as a function of season at Majete Wildlife Reserve, Malawi. Estimates are bounded in grey by a $95 \%$ confidence interval. 
majority of their time grazing (54.3\%). Five other studies conducted throughout Africa, indicated that zebra spend $60-70 \%$ of their time grazing (Beekman and Prins, 1989; Gakahu, 1984; Grogan, 1978; Rubenstein, 1994; Simpson et al., 2012). Across studies, plains zebra spent roughly half of their time feeding. The differences estimated between the amount of daylight time allocated to feeding between zebra in Majete compared to the rest of Africa may be due to differences in study design, may be indicative of greater nocturnal activity at Majete compared to other sites, or may reflect an actual difference in nutrient and energy availability or requirements (Beekman and Prins, 1989).

Seasonal variation in feeding behaviour of family bands in Majete was an important factor in their time budget, and combined with the significant decline in adult body condition concurrent with the advancing dry season, may indicate a seasonal lack of resources. Previous studies have found that in order for zebra and other equids to meet their energy requirements, $60 \%$ of their time needs to be allocated towards grazing under optimal conditions and $80 \%$ under poor conditions (Bell, 1971; Rubenstein, 1994; Tyler, 1972). In Majete during the wet season when food is abundant and of a high quality, family bands graze for $50.9-66.5 \%$ of the time compared to only $23.0-36.0 \%$ of the time during the dry season when grazing conditions were suboptimal. This decrease in the amount of time allocated to feeding during the dry season, instead of an increase as displayed by other studies, suggests that the availability of resources may be seasonally limited in Majete. The significant seasonal variation in the amount of time family bands allocate towards feeding in Majete confirms that the temporal and spatial abundance of resources shape the feeding behaviour of zebra (Rubenstein, 2010). It may be of concern for zebra in Majete if animals are unable to compensate for reduced food quality in the dry season by increasing their grazing time due to a lack of resources (Beekman and Prins, 1989). Our results suggest that Majete may not adequately include both summer and winter feeding areas given the current population size (Penzhorn and Novellie, 1991). Management action may be needed to supplement resources during extremely dry years or after extreme fires to prevent zebra mortalities.

Apart from season acting as a significant predictor of the feeding behaviour of family bands, age and foal presence also influenced feeding. Foals were observed feeding $17.3 \%$ more than adults in family bands. The difference in the amount of time foals allocated to feeding compared to adults may be a result of foals trying to meet the added energy demands of growth (Halle and Stenseth, 1997). In addition, females with foals grazed $20.0 \%$ more than individuals without foals. Other studies conducted on equids also observed lactating females spending more time grazing than non-lactating females (Boyd, 1988; Duncan, 1985, 1992; Neuhaus and Ruckstuhl, 2002). Females that are experiencing the added cost of producing milk for their foals (approximately 11-16 months until foals are weaned) may be forced to behave differently in order to meet their energetic requirements (Nuñez et al., 2011; Rubenstein, 1994). Age and reproductive state influences the energy requirements of family bands and in turn can result in a variation in time budgets (Halle and Stenseth, 1997).

\subsection{Bachelor bands}

In contrast to family bands that allocated $41.8 \%$ of their daylight time budgets to feeding, bachelor bands only appear to have fed $18.4 \%$ of the time. The largest proportion of bachelor band daylight time budgets was allocated towards vigilance $(26.9 \%)$. This proportionally corresponds to the findings of other studies in which bachelors were observed grazing 20-30\% less than family members, as males spend less time feeding and more time being vigilant (Rubenstein, 1994; Simpson et al., 2012). The variation in amount of time allocated towards feeding and vigilance between bachelor and family bands may thus be due to a variation in band composition. Bachelors generally occurred in smaller groups than family bands and therefore may have to allocate more time to vigilance behaviour in order to reduce predation risk (Rubenstein, 2010). Bachelor bands may also have lower energetic requirements than family band members, especially compared to females, and are therefore able to spend less time foraging and more time being vigilant (Clutton-Brock, 1991; Simpson et al., 2012). Variation in the amount of time allocated to vigilance and feeding between family and bachelor bands may also be influenced by observational bias, because it is unknown if bachelors were feeding in areas that were disproportionately not accessible to observers, or if bachelors spent more time feeding at night than family bands.

\subsection{Time period and season}

Our results suggest that both time period and season affected the vigilance behaviour of bachelors; similarly, both time period and age affected vigilance behaviour in family bands. On average adult zebra allocated an estimated $8.6 \%$ more time to vigilance behaviour than foals, indicating that it is the responsibility of the adult members of a family band to keep an eye out for predators and to protect their offspring from danger (King et al., 2016). This may explain why foals spent more time on maintenance behaviour than adults. Since foals spent less time on vigilance behaviour, they would be able to conversely spend more time on maintenance behaviour (especially grooming and play). It is important that foals are able to spend more time on maintenance behaviour because it develops their motor skills (Cameron et al., 2008; Khalil and Kaseda, 1998; Waring, 1983). Individuals who allocate more time to these types of behaviours improve their chance at survival by either improving their condition as a yearling or through the experiences learned through object play and play fighting (Cameron et al., 2008; King et al., 2016).

Family bands were significantly more vigilant in the morning (08:00-12:00 h) than any other time period (similar results were found in a study conducted by Simpson et al., 2012) and bachelors were significantly more vigilant in the afternoon (16:01-20:00 h). However, the amount of time allocated to being vigilant by both family and bachelor bands was lowest during midday (12:01-16:00 h). These results suggest that zebra decrease the amount of time allocated to vigilance behaviour when predation is less likely, since predators are generally inactive at midday (Hayward and Slotow, 2009). The amount of time bachelors allocated to vigilance was also significantly higher during the dry season than the wet season. This is likely due to the increased risk of being detected by predators in the dry season when compared to the wet season, due to the limited amount of vegetation cover during the dry season in Majete (Thaker et al., 2010). Predation thus likely shapes the vigilance behaviour of zebra in Majete, even though predator densities were unnaturally low.

Locomotion behaviour of family bands in Majete was greater during the late dry season (when rainfall was absent or limited) compared to all other times of the year. This suggests that the increase in daylight time allocated to locomotion in the late dry season in Majete was likely a result of the seasonal variation of resources. This concurs with other studies conducted on equids, which have also concluded that the amount of time spent moving is associated with a change in resources over seasons, since the relative distance between water sources and prime feeding areas increases during drier months (Berman, 1991; Brooks and Harris, 2008; Hampson et al., 2010; King et al., 2016).

Season influenced resting behaviour of family bands in Majete, with more time allocated to resting during the dry season (winter) than the late wet season (summer). This is in contrast to previous findings, as equids generally spend less time resting in the winter than in the summer (Keiper et al., 1980). This appears to be a consequence of the limited food resources during the dry season, resulting in a decrease in the amount of time allocated to feeding, which conversely increases resting time. Resting behaviour typically increases when feeding decreases, because of compositional trade-offs (King et al., 2016). Given the increase in nocturnal detections on our waterhole cameras during the dry season ( $31 \%$, as compared to $17 \%$ during wet season [deVos, 
2017]), it is possible that zebra were also compensating in part by becoming more active at night.

Group size did not directly affect the behaviour of zebra in Majete, but did interact with season to influence body condition. Typically for herbivores, an increase in group size will result in an increase in the amount of time allocated to feeding, since less time is allocated to vigilance behaviour as the risk of predation decreases (Ransom et al., 2010). However, an increase in group size can possibly also result in increased competition for feeding (Rubenstein, 1994). Zebra are extremely tolerant of one another due to the benefits of group living and this allows for a peaceful co-existence irrespective of group size (Rubenstein, 1994). It is hypothesized that to ensure the stability of family bands, synchronization of behaviour between different sexes within a family band should be high (Neuhaus and Ruckstuhl, 2002). The similarity in body mass between males $(250 \mathrm{~kg})$ and females $(220$ $\mathrm{kg}$ ) may be a prerequisite to allow for the synchronization of behaviour between the sexes (Estes, 1991; Owen-Smith, 1988; Ruckstuhl and Neuhaus, 2000). A variation in body mass between sexes generally results in different energetic requirements for females and males, which in turn leads to a sexual variation in time budgets (Neuhaus and Ruckstuhl, 2002).

\section{Conclusion}

Fourteen years after reintroduction, the plains zebra of Majete exhibit time budgets comparable to natural zebra populations; but seasonal variation in time spent feeding and resting - and consequently declining body condition - was detected, and may indicate a seasonal lack of adequate forage availability. The increased time in locomotion we detected may also represent a costly energy expenditure, compounding the effects of already limited resources during the dry season. Studies of seasonal diet and natural and artificial water source use may provide additional insights into how zebra select resources in the miombo savannah woodland habitat, and also may help explain the seasonal changes in locomotion behaviour we detected. This behavioural study provides important insights into resource implications for zebra in an ecological system with many large ungulate species that compete for forage. These findings may assist managers in identifying and mitigating changing resource conditions, and may consequently lead to better conservation and management of zebra toward sustaining healthy populations.

\section{Acknowledgements}

Thank you to African Parks (Pty) Ltd. for allowing us to live and conduct research in Majete Wildlife Reserve - it has been a privilege. Many thanks to Willem D. Briers-Louw for assisting with numerous zebra behavioural sessions. Professor Martin Kidd provided valuable assistance with the statistical analyses. Thank you to the all the Earthwatch volunteers of 2016 who helped with the data collection for this project, as well as the Earthwatch Institute for funding the Animals of Malawi in the Majete Wildlife Reserve Project. Thanks to the Albright-Wirth Grant Program for supporting the U.S. National Park Service contributions to this research. This research did not receive any other specific grant from funding agencies in the public, commercial, or not-for-profit sectors. Any use of trade, product, or firm names is for descriptive purposes only and does not imply endorsement by the U.S. Government.

\section{References}

Beekman, J.H., Prins, H.H.T., 1989. Feeding strategies of sedentary large herbivores in East Africa, with emphasis on the African buffalo, Syncerus caffer. African J. Ecol. 27, 129-147. https://doi.org/10.1111/j.1365-2028.1989.tb00937.x.

Bell, R.H.V., 1971. A grazing system in the Serengeti. Sci. Am. 225, 86-93. https://doi. org/10.1038/scientificamerican0771-86.

Berman, D.M., 1991. The Ecology of Feral Horses in Central Australia. Ph.D. Dissertation.
University of New England, Armidale.

Boyd, L., 1988. Time budgets of adult Przewalski horses: effects of sex, reproduction status and enclosure. Appl. Anim. Behav. Sci. 21, 19-39. https://doi.org/10.1016/ 0168-1591(88)90099-8.

Brooks, C.J., Harris, S., 2008. Directed movement and orientation across a large natural landscape by zebras, Equus burchelli antiquorum. Anim. Behav. 76, 277-285. https:// doi.org/10.1016/j.anbehav.2008.02.005.

Cameron, E.Z., Linklater, W.L., Stafford, K.J., Minot, E.O., 2008. Maternal investment results in better foal condition through increased play behaviour in horses. Anim. Behav. 76, 1511-1518 https://doi.org/10.1016.j.anbehav.2008.07.009.

Clutton-Brock, T.H., 1991. The Evolution of Parental Care. Princeton University Press, Princeton.

De Vos, C., 2017. Ecology of Plains Zebra (Equus quagga) in Majete Wildlife Reserve, Malawi. M.S. Thesis. Stellenbosch University. http://hdl.handle.net/10019.1/ 102624.

Duncan, P., 1985. Time-budgets of camarque horses: III. Environmental influences. Behaviour 92, 188-208. https://doi.org/10.1163/156853985X00442.

Duncan, P., 1992. Horses and Grasses: The Nutritional Ecology of Equids and Their Impact on the Camargue. Springer-Verlag, New York.

Estes, R.D., 1991. The Behaviour Guide to African Mammals, Including Hoofed Mammals, Carnivores, Primates. University of California Press, Berkeley.

Gakahu, C., 1984. Feeding Ecology of Plains Zebra in Amboseli National Park. Ph.D. Dissertation. University of Nairobi.

Gelman, A., Hill, J., 2007. Data Analysis Using Regression and multilevel/hierarchical Models. Cambridge University Press, New York, USA.

Grange, S., Barnier, F., Duncan, P., Gaillard, J.-M., Valeix, M., Ncube, H., Périquet, S., Fritz, H., 2015. Demography of plains zebra (Equus quagga) under heavy predation. Popul. Ecol. 57, 201-214. https://doi.org/10.1007/s10144-014-0469-7.

Grogan, P., 1978. Feeding Ecology of Plains Zebra in the Serengeti. M.S. Thesis. Texas A\& M University, College Station.

Hack, M.A., East, R., Rubenstein, D.I., 2002. Status and action plan for the Plains zebra (Equus burchellii). In: Moehlman, P. (Ed.), Equids: Zebras, Asses and Horses-Status Survey and Conservation Action Plan. IUCN/SSC Equid Specialist Group, Cambridge, pp. 43-60.

Halle, S., Stenseth, N.C., 1997. Activity Patterns in Small Mammals: an Ecological Approach. Springer-Verlag, Berlin.

Hampson, B.A., de Laat, M.A., Mills, P.C., Pollitt, C.C., 2010. Distance travelled by feral horses in "outback"Australia. Equine Vet. J. 42, 582-586. https://doi.org/10.1111/j. 2042-3306.2010.00203.x.

Hayward, M.W., Slotow, R., 2009. Temporal partitioning of activity in large African carnivores: tests of multiple hypotheses. S. Afr. J. Wildl. Res. 39, 109-125. https:// doi.org/10.3957/056.039.0207.

Henneke, D.R., Potter, G.D., Kreider, J.L., Yeates, B.F., 1983. Relationship between body condition score, physical measurements and body fat percentage in mares. Equine Vet. J. 15, 371-372. https://doi.org/10.1111/j.2042-3306.1983.tb01826.x.

Keiper, R.R., Moss, M., Zervanos, S., 1980. Daily and seasonal patterns of feral ponies on Assateague Island. Conference on Scientific Research in the National Parks, vol. 2. pp. 369-381.

Khalil, A.M., Kaseda, Y., 1998. Early experience affects developmental behaviour and timing in harem formation in Misaki horses. Appl. Anim. Behav. Sci. 59, 265-276. https://doi.org/10.1016/S0168-1591(98)00111-7.

King, S.R.B., Asa, C., Plucháček, J., Houpt, K., Ransom, J.I., 2016. Behaviour of horses, zebras, and asses. In: Ransom, J.I., Kaczensky, P. (Eds.), Wild Equids: Ecology, Management, and Conservation. Johns Hopkins University Press, Baltimore, pp. 23-40. https://doi.org/10.1353/book.47460.

Klingel, H., 1969. The social organization and population ecology of the plains zebra, Equus quagga. Zool. Afr. 4, 249-263. https://doi.org/10.1080/00445096.1969. 11447374.

Krebs, J.R., Davies, N.B., 1997. Behavioural Ecology: An Evolutionary Approach. Blackwell Publishing, Oxford.

Neuhaus, P., Ruckstuhl, K.E., 2002. The link between sexual dimorphism, activity budgets, and group cohesion: the case of the plains zebra (Equus burchelli). Can. J. Zool. 80, 1437-1441. https://doi.org/10.1139/Z02-126.

Nuñez, C.M.V., Asa, C.S., Rubenstein, D.I., 2011. Zebra reproduction. In: McKinnon, A.O. Squires, E.L., Vaala, W.E., Varner, D.D. (Eds.), Equine Reproduction. WileyBlackwell, West Sussex, pp. 2854-2866.

Owen-Smith, N., 1988. Megaherbivores: The Influence of Very Large Body Size on Ecology. Cambridge University Press, London.

Penzhorn, B.L., Novellie, P.A., 1991. Some behavioural traits of Cape mountain zebras (Equus zebra zebra) and their implications for the management of a small conservation area. Appl. Anim. Behav. Sci. 29, 293-299. https://doi.org/10.1016/01681591(91)90255-V.

Ransom, J.I., Cade, B.S., 2009. Quantifying Equid Behaviour - A Research Ethogram for Free-roaming Feral Horses. Techniques and Methods 2-A9. US Geological Survey, Virginia.

Ransom, J.I., Cade, B.S., Hobbs, N.T., 2010. Influences of immunocontraception on time budgets, social behaviour and body condition in feral horses. Appl. Anim. Behav. Sci. 124, 51-60. https://doi.org/10.1016/j.applanim.2010.01.015.

Ransom, J.I., Kaczensky, P., 2016. Wild Equids: Ecology, Management, and Conservation. Johns Hopkins University Press, Baltimore. https://doi.org/10.1353/book. 47460.

Rubenstein, D.I., 1994. The ecology of female social behavior in horses, zebras and asses. In: Jarman, P., Rossiter, A. (Eds.), Animal Societies: Individuals, Interactions and Organization. Kyoto University Press, Kyoto, pp. 13-28.

Rubenstein, D.I., 2010. Ecology, social behavior, and conservation in zebras. In: In: Macedo, R. (Ed.), Advances in the Study Behaviour: Behavioural Ecology of Tropical Animals 42. Elsevier Press, Oxford, pp. 231-258. 
Rubenstein, D.I., Hack, M., 2004. Natural and sexual selection and the evolution of multilevel societies: insights from zebras with comparison to primates. In: Kappeler, P.M., van Schaik, C.P. (Eds.), Sexual Selection in Primates: New and Comparative Perspectives. Cambridge University Press, Cambridge, pp. 266-279.

Ruckstuhl, K.E., Neuhaus, P., 2000. Sexual segregation in ungulates: a new approach. Behaviour 137, 361-377. https://doi.org/10.1163/156853900502123.

Rudman, R., Keiper, R.R., 1991. The body condition of feral pones on Assateague Island. Equine Vet. J. 23, 453-456. https://doi.org/10.1111/j.2042-3306.1991.tb03760.x.

Sibly, R.M., Smith, R.H., 1985. Behavioural Ecology: Ecological Consequences of Adaptive Behaviour. Blackwell Scientific, Oxford.

Simpson, H.I., Rands, S.A., Nicol, C.J., 2012. Social structure, vigilance and behaviour of plains zebra (Equus burchellii): a 5-year case study of individuals living on a managed wildlife reserve. Acta Theriol. 57, 111-120. https://doi.org/10.1007/s13364-0110061-x.

Thaker, M., Vanak, A.T., Owen, C.R., Ogden, M.B., Slotow, R., 2010. Group dynamics of zebra and wildebeest in a woodland savanna: effects of predation risk and habitat density. PLoS One 5, e12758. https://doi.org/10.1371/journal.pone.0012758.

Tyler, S.J., 1972. The behaviour and social organization of the New Forest ponies. Anim. Behav. 5, 85-196. https://doi.org/10.1016/0003-3472(72)90003-6.

Waring, G.H., 1983. Horse Behavior: the Behavioural Traits and Adaptations of Domestic and Wild Horses, Including Ponies, first ed. Noyes Strategic Publication, Saddle River. 